\title{
Prospects of Rural Transformation Centre (RTC) of Malaysia from the Perspective of Inclusive Rural Development
}

\author{
SHAWON MUHAMMAD SHAHRIAR ${ }^{\star 1}$, CHAMHURI SIWAR $^{1}$, \\ ROSPIDAH GHAZALI ${ }^{1}$ and NORSHAMLIZA CHAMHURI ${ }^{2}$
}

\author{
${ }^{1}$ Institute for Environment and Development (LESTARI), The National University of Malaysia (UKM), \\ 43600 Bangi, Selangor Darul Ehsan, Malaysia. \\ ${ }^{2}$ Faculty of Economics and Management, The National University of Malaysia (UKM), Malaysia.
}

http://dx.doi.org/10.12944/CWE.9.3.12

(Received: October 25, 2014; Accepted: November 12, 2014)

\begin{abstract}
In the contemporary discourse, it is argued that the ultimate objective of rural development is to improve the quality of life for rural people. This makes it essential to go beyond the incomerelated factors of rural development. Inclusive Rural Development, a more specific concept than the concept of conventional rural development, accommodates the variables for the quality of life in rural development. This concept covers three different but interrelated dimensions: economic dimension, social dimension and political dimension. Rural Transformation Centre (RTC), implemented by the government of Malaysia, is among the third generation of the rural development programmes in the country. RTC is a site to implement some integrated initiatives for the rural communities within 100 kilometre radius of the sites. There are eight major initiatives under the RTC implementation programmes, which are: training of rural population; setting up of 1 Malaysia information kiosks; high-value agriculture initiatives; agro-food products processing; agricultural produce supply chain management; university cooperation; food safety and pharmaceuticals services; and rural population financial facilities. RTC brings a unique opportunity for members of the rural communities to benefit from a myriad of initiatives and activities related to their livelihood and wellbeing within the same premises. Despite some challenges, this programme has enormous potentials to address many important aspects of rural development. Based on review of relevant literature and field visits, this paper attempts to examine the prospects of the RTC concept of Malaysia in light of the theory of Inclusive Rural Development. The findings of this paper will help relevant governmental and nongovernmental bodies and researchers gain an insight about the potentials and challenges of RTC for further improving the quality of life for the rural communities.
\end{abstract}

Key words: Rural Transformation Centre (RTC), Rural development, Inclusive rural development, Rural livelihood.

\section{INTROUDUCTION}

The concept of rural development has undergone significant changes in last few decades (Harris 1982; Chambers 1983; ADB 2000). Until the 1970s, rural development and agricultural development used to be synonymous, where the primary focus was on increasing agricultural production. During that period, most countries were promoting smallholder agriculture to achieve the objective of increasing production in the agricultural sector. Over time, this concept of smallholder agriculture-centric rural development went through significant changes. By the early 1980s, a new definition of rural development was adopted by the World Bank, which defined it as "...a strategy designed to improve the economic and social life of a specific group of people-the rural poor" (Harris 1982). There was a paradigm shift in the discourse of development in general with the establishment of the Millennium Development Goals (MDGs) by the United Nations in the year 2000, where the significance of non-income poverty was reinforced by committing to help achieve eight Millennium 
Development Goals by the year 2015 (The United Nations 2014). With this paradigm shift in discourse, the concept of rural development started to incorporate broader dimensions than rural poverty. In the recent years, environmental aspects of economic growth have gained prominence in the discourse of development. The contemporary concept of rural development encompasses "concerns that go well beyond improvements in growth, income, and output. The concerns include an assessment of changes in the quality of life, broadly defined to include improvement in health and nutrition, education, environmentally safe living conditions, and reduction in gender and income inequalities" (Chino 2000). According to this definition, improving the quality of life for the rural people is the ultimate objective of rural development. As a consequence, it becomes essential to go beyond the income-related factors to a range of non-income factors that influence the quality of life for the rural people.

In East Asia, Japan, Taiwan and South Korea achieved a significantly high level of rural development primarily through their structural transformation process during the 1950s to the late 1970s. Agricultural development played a critical role in rural development in these economies. These three economies also adopted development policies with emphasis on adequate investments in basic services for the rural population and promotion of social development for them. They ensured adequate facilities for both primary health care and primary education for rural population at the early stages of their growth, which contributed to reduce rural-urban inequalities. Moreover, egalitarian land distribution policies further reduced rural-urban inequalities in income and social indicators (Nimal 2008).

Malaysia, classified as a middle-income country in the East Asia region, was also remarkably successful in rural development through its structural transformation in the 1980s and 1990s. High overall economic growth, reasonably high growth rates in agriculture, rural nonfarm employment and ruralto-urban migration contributed to enhanced rural development in the country and millions of rural households, largely farm households, were able to improve their socioeconomic well-being and escape poverty. However, the concern of non-income poverty still has significance for Malaysia for various reasons: firstly, most people with low social development are concentrated in rural areas; secondly, significant intra-sectoral disparities in social development exist in rural areas; and thirdly, social development in rural areas continues to be much lower than that in urban areas (Nimal 2008).

In order to address the concern of rural non-income poverty and other relevant social and economic indicators affecting the rural population, the government of Malaysia has undertaken many projects and initiatives involving several ministries and executing agencies. Rural Transformation Centre (RTC) is an example of these initiatives undertaken by the federal government of the country. It is a central facility established by the government to incorporate nearby villages in high value-added product oriented activities with the objective of enhancing market competitiveness in rural communities by enabling improvement in the quantity and quality of their products. According to its mandate, an RTC is supposed to improve the living conditions of people living in rural communities around 100 kilometre radius of the centre (Ministry of Rural and Regional Development 2013). Based on reviewing relevant literatures and field visits by the authors, this paper attempts to investigate whether the RTC concept is in alignment with the theory of Inclusive Rural Development, which deals with the issue of improving the quality of life for all members of the rural society.

\section{METHODS AND MATERIALS}

\section{Rural Development Policies of Malaysia}

Malaysia, one of the most advanced economies of South-East Asia, has witnessed a relatively high and sustainable rate of economic growth since it became an independent country. In the early days of the nation, the policy makers were inclined to a laissez faire approach for economic development. As a consequence, infrastructure projects, such as construction of roads and irrigations projects were the primary focus by the government for rural development. Besides them, various projects on education, skills training, health care services, and utility services like providing electricity, water and sewerage lines were in the agenda. This era also witnessed the initiation of land settlement schemes and protraction of rice price stabilisation programmes 
that began after the Second World War. There were also attempts to advance agricultural marketing activities through cooperatives, but it did not succeed in the long run (Rudner 1975).

In the 1970s, the Federal Agricultural Marketing Authority (FAMA) was reorganised to provide market information. Moreover, the Malaysian Agricultural Bank, currently known as Agrobank, was established to provide loans for agricultural activities. The other major initiatives undertaken or expanded during that era were the National Paddy and Rice Authority to support the prices of rice, the Farmers Organisation Act for other crops, the National Livestock Development Authority, expansion of the Federal Land Development Authority, the Federal Land Consolidation and Rehabilitation Authority, the Rubber Industry Smallholders Development Authority, and an association for oil palm producers (Mehmet 1986).

The agricultural sector remained an important component of the five year plans of the country and its New Economic Policy (NEP). However, the recession of the 1980s induced the policy makers of the country to re-evaluate its existing agricultural policies and programmes. Subsequently, a National Agricultural Policy (NAP) was adopted in 1984. The stated primary objective of this policy was to maximise incomes from the agricultural sector through efficient utilisation of the resources of the country, and by revitalising the agricultural sector's contributions to the overall economic development of the country (Malaysia 1992). This new policy prompted a set of programmes and activities, such as new land development, promotion of efficient agricultural practices, establishment of economically viable farm units, introduction of new higher-valued crops, and an expansion of support services in research, marketing of agricultural products, financial incentives for farming, and institutional and social development. At the same time, agroindustrial enterprises were promoted to enhance the productivity and income from the agricultural sector through various value added activities. Despite the enormous economic growth of the country in last couple of decades, rural development remains an important aspect of development planning in Malaysia, arguably because poverty and inequality in rural communities still persist.

\section{An Overview of the Rural Transformation Centre (RTC) Concept}

Rural Transformation Centre (RTC), implemented under the National Blue Ocean Strategy 4 (NBOS4) by the government of Malaysia, is a site to implement some integrated initiatives for the rural communities within 100 kilometre radius of the site. There are eight major initiatives under the RTC implementation programmes, which are: training of rural population; setting up of 1 Malaysia information kiosks; high-value agriculture initiatives; agro-food products processing; agricultural produce supply chain management; university cooperation; food safety and pharmaceuticals services; and rural population financial facilities. The implementation of these initiatives is led by various ministries with the support and cooperation from other relevant ministries.

Under the initiative of skills training for rural population, The Ministry of Rural and Regional Development (KKLW) provides training opportunities to rural communities with the objective of enhancing their knowledge, skills and abilities so that they can get better job opportunities, earn more money and improve their living standards. Some of these training initiatives are in the areas of entrepreneurship, entrepreneurial motivation, packaging and branding, product performance, animal feed management, tertigation techniques, air conditioner repair skills, and welding skills.

1 Malaysia information kiosks, a onestop information centre that combines information and services offered by various ministries and government agencies, is another initiative of the RTC. Five information kiosks located at the RTCs will offer a variety of services, which are: KKLW kiosk to provide InfoDesa (Information Village) information and agencies' mailing system; Malaysia jobs kiosk to offer employment opportunities; Agrofood Business Development Centre kiosk to allow people receiving information on agro-food business and community development; KPDNKK kiosk to facilitate consumerism issues like the Price Watch current price forums and users' SMS application service; and MyEG kiosk to facilitate receiving a range of useful information of various government agencies. 
Under the initiative of high-value agriculture, there are three ongoing and planned major projects, which are: premium vegetable production, dairy production project, and arowana fish breeding project. Under the premium vegetable production project at Lojing Food Production Permanent Park, some high in demand vegetables, such as tomato and capsicum, are produced. Under the safe and quality daily production project, the Dairy Industry Service Centre (PPIT) assists small-scale dairy farmers to market their raw milk. In addition, PPIT also provides technical advice and carries out tests on the quality of milk. PPIT is proposed to purchase raw milk and market them to processing plants to produce pasteurised milk, yoghurt, buttermilk and ice-cream. Arowana fish breeding project, which is yet to be implemented, is a high-value industry and has good potentials for earning high rate of returns.

The initiative agro-food products processing, aiming at developing food processing enterprises in the field level, emphasises on the development and improvement in agro-food product quality for local and overseas markets. RTC Perak, in particular, is focusing on the following agro-food products: traditional cakes, virgin coconut oil, citrus fruits, salted eggs, juice, sauce, chips, frozen food and herbs. This initiative is supposed to support agrobased industry development through value added activities and improvement of income for the farming communities.

The initiative agricultural produce supply chain management is planned to re-rationalise the marketing concept of agricultural products through the management of supply chain from farms to consumers. This involves prudent planning, efficient execution, and appropriate control in the supply chain of agricultural products, particularly in movement and storage of raw materials, inventories and finished products from the points of production to the points of consumption.

The initiative university cooperation aims at creating awareness through students to produce a knowledgeable society with the objective of enhancing the socioeconomic status of rural communities. Lead by the Ministry of Higher Education, the volunteering activities under this initiative are Rural Ambassador, Educate Malaysia and Health for Malaysia.

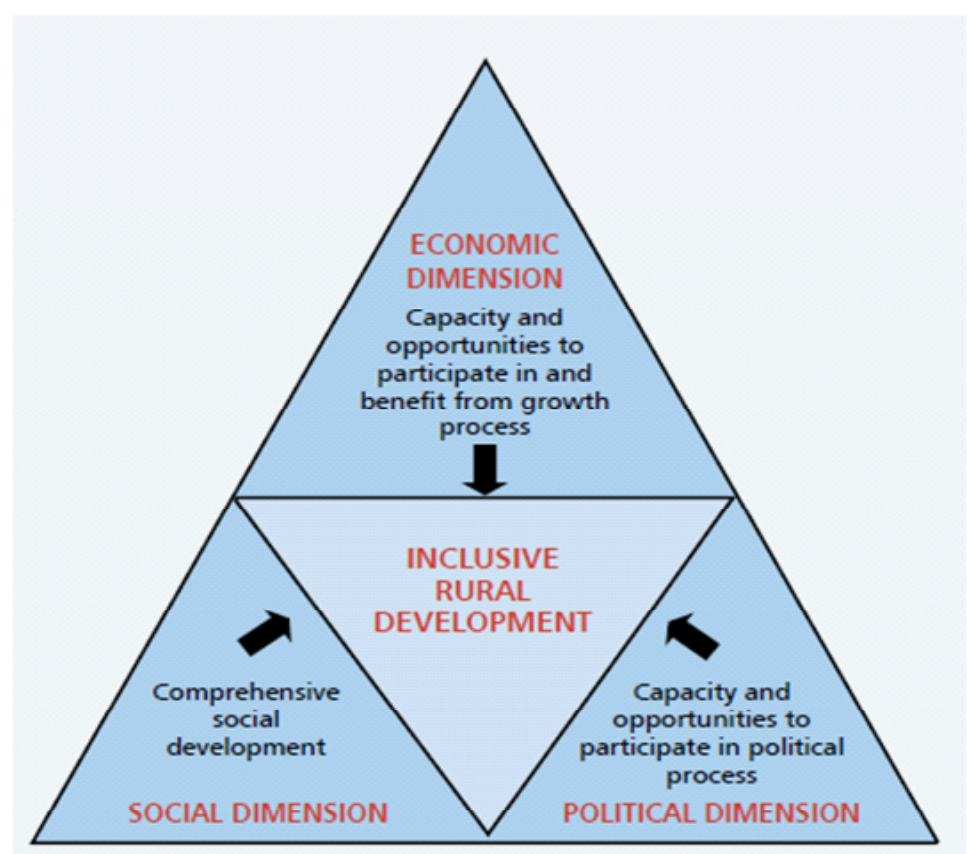

Fig. 1: The three dimensions of inclusive rural development (Nimal 2008) 
The initiative food safety and pharmaceutical services, offered by the Ministry of Health, incorporates mainly two programmes: technical advisory services for food safety assurance, and traditional medicines and cosmetics. Under the technical advisory service for food safety assurance programme, the Food Safety and Quality Division (BKKM) helps the food industry - especially for small and medium industries - to produce safe food by offering some recognitions. Under the technical advisory for security assurance of traditional medicines and cosmetics programme, the National Pharmaceutical Control Bureau assists the traditional medicine and cosmetics product producers in the registration and notification of their companies' products. The bureau ensures that modified cosmetics produced locally or registered traditional products are of good quality, and safe and effective.

The initiative rural population financing facilities, implemented by the Ministry of Finance in collaboration with various financial institutions and government agencies, provides micro credit facilities to borrowers at RTCs at low interest or profit rate to help the entrepreneurs conducting their business activities in RTC. The financial institutions and funding facilities that are operating or are planned to operate at RTC are: Rural Economy Financing Scheme (SPED), Bank Simpanan Nasional, Agrobank, Perbadanan Ushawan Nasional Berhad (PUNB), TEKUN Nasional, SME Bank, MARA Entrepreneur Guarantee Scheme (SJUM), Yayasan Pembangunan Ekonomi Islam and Amanah Ikhtiar Malaysia (AIM).

\section{The Theory of Inclusive Rural Development}

In broad terms, inclusive rural development is about improving the quality of life of all members of rural society. To be specific, this theory covers three different yet interrelated dimensions of rural development, namely economic dimension, social dimension and political dimension (Nimal 2008). The economic dimension of inclusive rural development encompasses providing both capacity and opportunities for poor and low-income rural households in particular to benefit from the economic growth process in such a way that their average incomes grow at a higher rate than the growth of average incomes in the sector as a whole (UNDP 2005). The economic dimension also includes measures to reduce intra- and intersectoral income inequalities to reasonable levels. The social dimension of inclusive rural development encompasses supporting social development of the poor and low-income households and underprivileged groups, minimising inequalities in various social indicators, promoting women empowerment and gender equality, and providing social safety nets for vulnerable groups. The political dimension of inclusive rural development encompasses enhancing opportunities for the poor and low-income people in rural areas, women and ethnic minorities in particular, to participate in the political process at the village level and beyond equally and effectively.

Scholars and practitioners differ over defining what the most important drivers of inclusive rural development are; the diversity of country contexts makes it even more difficult to offer firm answers to these questions (Sen 2006). Moreover, the global context in which countries operate today is different and it continues to change; resource endowments and economic characteristics across countries also differ. However, despite these challenges, and many other cross-country differences, the development experience over the last five decades seems to offer some insights on what is likely to drive rural development and what could make it more inclusive. Based on these insights, the key drivers of inclusive rural development are: high overall economic growth, effective land reform, rural infrastructure, effective institutions, rural financial services, a dynamic agricultural sector, rural non-farm enterprises, and subsidies (Nimal 2008).

\section{DISCUSSION}

Rural Transformation Centre (RTC) is among the third generation of the rural development programmes in Malaysia, green revolution being the first one and building up of essential rural infrastructures being the second. The programme has already been implemented in the states of Perak and Kelantan in comparatively large scale, and in Malacca and Pahang in a smaller scale. The government of Malaysia has a plan to rollout RTCs in the remaining states across the country. Among the eight major initiatives of the RTC concept, some have already been executed at some of the states 
and others are in the pipeline for implementation when circumstances allow.

Among the three dimensions of inclusive rural development, the RTC concept primarily incorporates two of them, namely economic dimension and social dimension, economic dimension being the main driver. With regard to the economic dimension of social development, the RTCs should be able to provide capacity and opportunities for the surrounding rural communities so that they are able to benefit from the overall economic growth of the country by increasing their average household incomes. It is expected that if implemented as per plans, the RTCs will enhance market access for agricultural and agro-based commodities and products for the surrounding rural communities that will have a cascade down effect on members of these communities through more employment opportunities, business opportunities and income opportunities. Among the eight major initiatives of the programme, rural population financing facilities, highvalue agriculture, agro-food products processing, and agricultural produce supply chain management are directly related to the economic dimension of inclusive rural development. Additionally, skills training for rural population, and food safety and pharmaceutical services will enhance skills and access of the local community members, which will be translated into long-term economic benefits for them.

Once the members of the surrounding rural communities start enjoying the direct and indirect economic benefits through successful implementation of these major initiatives of RTCs, they will be able to spend more money on their social needs such as education and better healthcare services. Additionally, the presence of many government agencies providing basic and essential services for the rural communities at the RTC premises will lead to better accessibility to these needed services. The presence of several information kiosks and other activities throughout the year will enhance access to information for the community members. It can be argued that these expected social benefits are residual effects of the economic benefits of the RTCs, because supporting social development for the poor and low-income households and underprivileged groups, minimising various indicators of inequalities, empowering women and equal treatment to them, and social safety net for vulnerable groups - which are integral components of the social dimension of inclusive rural development - can hardly be achieved through an on-sight infrastructure based project like the RTC. However, the RTC can play a supportive role within its own capacity with other governmental and non-governmental programmes and initiatives that are dealing with the rural communities.

With regard to the political dimension of inclusive rural development, the RTC programme is not mandated to facilitate in better political participation at the village level. The programme primarily offers various socioeconomic benefits and opportunities for the rural communities. It can be argued that, if the community members benefit from them, they will have a better say in the political process within their respective localities. The absence of offering tangible political benefits should not be considered a weakness for the RTC concept, because there are many other avenues open to address this particular issue. Moreover, considering the nature of politics itself, it should not be ruled out that incorporating political components may undermine the long-term socioeconomic prospects of the RTCs.

The RTC concept should be a welcome move for the members of surrounding rural communities, because it has enables them to avail skills training, receive numerous governmental services, explore business opportunities, and access needed information within the same premises. The government of Malaysia has created a unique platform to incorporate all these activities and assembled almost all agencies dealing with the rural communities for their services. Nevertheless, the ultimate success of this programme depends greatly on the participation and response from the community members for whom all these initiatives and activities have been undertaken.

\section{CONCLUSION}

The theory of inclusive rural development is a good benchmark to measure the actual merits of a rural development programme from economic, social and political dimensions. The Rural Transformation Centre (RTC) is an on-sight infrastructure based 
project by the government of Malaysia, where the lion's share of focus goes to the economic dimension of rural development. There are some indirect effects on social dimension of rural development and apparently very negligible effects on the political dimension. Given the nature of the programme and its ultimate mandate, it is not an umbrella initiative for inclusive rural development, rather a programme to support other governmental and non-governmental initiatives of rural development. If inclusive rural development is considered as a complete set, the RTCs without any doubt will quality as an important subset. The programme is yet to be implemented in most of the states of Malaysia and have been implemented partially in four states. Once the programme is implemented completely in the near future across Malaysia, further studies can be conducted to determine the real impacts of the programme upon the surrounding rural communities in the context of inclusive rural development.

\section{ACKNOWLEDGEMENT}

This paper is supported by the Institute for Environment and Development (LESTARI), The National University of Malaysia (UKM) and revived funding from projects "Effectiveness and benefits of Rural Transformation Programme (RTC)" (DPP2014-081), and "Rural Transformation for Sustainable Livelihood" (AP-2014-017), for which the authors are grateful.

\section{REFERENCES}

1. Harris, J., General Introduction in Rural Development: Theories of Peasant Economy and Agrarian Change, Hutchinson University Library, London (1982)

2. Chambers, R., Rural Development: Putting the Last First, Longmen, London (1983)

3. Asian Development Bank (ADB), Rural Asia: Beyond the Green Revolution, ADB, Manila (2000)

4. The United Nations. New York, USA. http:// www.un.org/millenniumgoals/bkgd.shtml (last accessed: 10 September 2014).

5. Chino, T., In Transforming the Rural Asian Economy: The Unfinished Revolution, Oxford University Press, Hong Kong (2000)

6. Nimal A., F., EARD Special Studies: Rural Development Outcomes and Drivers - An Overview and Some Lessons, ADB, Manila (2008)

7. Ministry of Rural and Regional Development.
Putrajaya, Malaysia. http://www.rurallink. gov.my/web/guest/pusat-transformasi-luarbandar-rtc- (last accessed: 15 March, 2013).

8. Rudner, M., Nationalism, Planning and Economic Modernization in Malaysia: The Politics of Beginning Development, Croom Helm Ltd., Kent (1975)

9. Mehmet, O., Development in Malaysia, Croom Helm Ltd., London (1986)

10. Malaysia, Office of the Prime Minister, The National Agricultural Policy, 1992-2010, Government Press, Kuala Lumpur (1992)

11. United Nations Development Program (UNDP), Human Development Report 2005, UNDP, New York (2005)

12. Sen, A., The Man Without a Plan (book review: White Man's Burden by William Easterly), Foreign Affairs 85(2):171-177, (2006) 